\title{
Analysis and Motivation for Green Computing, an Approach in India
}

\author{
P.K. Manoj Kumar
}

\begin{abstract}
Green Computing has made significant approach towards the rethink environmental impact of technology. Green or else environment friendly computing attempts towards reducing consumption of energy in the direction of reducing consumption of fuel required towards producing it so as to entails the toxic impact on environment. The rising require intended for tighter energy budgets demands vigilant energy conservation in addition to therefore driving us towards propose energy aware hardware in addition to software. Effective Energy conservation though is an accumulation of both designs in addition to best practices.
\end{abstract}

Keyword--- Green Computing, Eco-friendly Computing, E-Waste Management

\section{INTRODUCTION}

$\mathrm{T}$ HE importance of green computing is the energy conservation. The conservation of energy may be towards reducing e-wastes. Through Cloud computing the distribution of the program on dissimilar machines has gained a great deal popularity as it reduces execution time in excess of a network. Towards solving a large computationally intensive problem, a cluster of numerous low capacity machines is additional advantageous in terms of cost in addition to performance compared towards a high capacity machine. The additional energy was consumed by high machines as the resources was not utilized properly. The energy conservation may be implemented through cloud computing among green strategies implementation to improve the performance.

Optimizations intended for energy conservation can be made at hardware in addition to software levels. The performance of hardware level energy may be increased through smaller silicon procedure geometrics with addition to active well biasing techniques. Software level energy optimization are implemented in operating system in the course of Green Scheduling techniques so as to analyze active processes intended for energy requirements in addition to by means of the Green Compilers through program analysis at compile time in addition to code reshaping during transformations. Energy can moreover be conserved, during software development life cycle such as software analysis in addition to design, through applying dissimilar green aspects mentioned further in succeeding sections.

Green information technology (IT) is connected by means of concepts similar to reducing energy consumption, recycling obsolete products as well as waste, eliminating hazardous

P.K. Manoj Kumar, Head, Department of Information Technology, Nehru Arts and Science College, Coimbatore - 641105, Tamil Nadu, India. E-mail:manoj0726@yahoo.com

DOI: 10.9756/BIJNTA.7138 substances in addition to reducing carbon footprint. Green Computing provides resource optimization similar to virtualization as same as cloud computing in reducing business travel and use of shared resources.

\section{METHODS FOR GREEN COMPUTING}

There are numerals of additional basic steps that can be taken towards considerably reducing the environmental impact of computing. These mostly involve measures intended for reducing energy consumption.

\section{Lower Power Hardware}

Solid state disk (SSD) may be used in place of spinning hard drive system disk in addition towards usage of less electricity and low power processor.

\section{Virtualization}

Physical servers may be replaced virtual servers to run as software on a little number of large computers as virtualization is the use of computer software towards simulates hardware, through a virtualized server consolidation a company can attain a far additional optimal use of computing resources through removing the idle server capacity that is frequently spread across of physical servers.

\section{Cloud Computing}

Cloud Computing is the technology that software applications are accessed with the use of internet. Through this technology anybody may obtain the environmental benefits of virtualization. It reduces the carbon footprint. Cloud computing replaces the high power PCs in addition to laptop.

\section{Less Pollutant Manufacture}

More number of chemicals like lead, mercury, cadmium, beryllium, bromine flame retardants, polyvinyl chloride are used in terms of quantity to make computers. Through reducing the use of such substances, hardware manufacturers might prevent folks being exposed towards them, in addition to enabling additional electronics waste towards is safely recycled.

\section{Wireless Network and Sensors}

Sensors can be employed in dissimilar parts areas in a data center towards determine the temperature of every area. This way it will be simply known which area needs additional cooling as well as where towards reducing the cooling.

\section{Recycle}

Recycling the unwanted electronic equipments are responsible for environment sustaninability. All the computers contains toxin metals so as to emit harmful emissions in to the environment. 


\section{Reduce PAPER USE: Simple SUGGestion}

Our computer labs on campus go throughout at least one tree's worth of paper each week.

One can assist decreasing this waste through subsequent a few of these easy steps:

- Use Print Preview towards review documents prior to printing them.

- While you are in the print preview mode, check to see if really needs the entire the pages of document printed.

- As soon as writing papers, use the smallest size text font so as to determination be comfortably read.

- Archive email through saving it towards a folder, rather than printing it.

- Think twice prior to printing something as of the web; considering bookmarking the pages instead or else emailing you a link towards the page.

- If require towards taking print a website intended for the text content, consider copying as well as pasting the content towards a word processor, where edit out unwanted content in addition to reduce font size.

- Printing multiple copies of documents is additional energy efficient at the duplicating center.

Recycle Ideas: Common Human thoughts

If even one follows these suggestions, our world determination is a better place. However imagine if everyone on campus able towards implementing a number of these changes. Spread the word concerning this research in the direction of friends, colleagues as well as families.

\section{Global Impact}

Over 850 million PCs are turned on each day. If NComputing systems were utilized at a ratio of 6 NComputing devices towards every PC:

- Energy use would decline by means of over 120 billion kilowatt hours an year.

- $\mathrm{CO} 2$ emissions would reduce by means of 96 million metric tons; it is similar to planting 460 million trees.

- E-waste would be reduced by means of 6.7 million metric tons.

\section{Advantages}

- Efficiently share one PC by means of up to 30 users as its design enables it towards maximize the power of PC's as well as Servers.

- Dramatically reduce acquisition and support costs as $\mathrm{N}$ Computing costs less than legacy PC technologies in addition to uses up to $95 \%$ less power.

- Easy towards set up, maintain as well as secure as the device is simply a media conduit towards the main PC or else Server and as no intelligence is held on it can contain no sensitive information.

\section{NEED OF GREEN COMPUTING}

Mainly of the computer energy is frequently wasteful. This is since leaving the Computer ON even while it is not in use. Defects in Manufacturing techniques, packaging, and disposal of computers in addition to components cause environmental pollution. Information Technology energy demand is growing 12 times faster than the general demand intended for energy. Data center emits over 150 metric tons of $\mathrm{CO} 2$ per year in addition to the volume is increasing rapidly. Computing power consumption of companies has reached a crucial point.

\section{Solar Computing}

One of the methods for non-polluitng the environment in addition to highly reliable is solar computing as it fits power comprtent silicon, whch enables the company towards developing fully solar powered devices. The intial cost of solar computing is high and little maintenance all through life time. Worldwide production of solar cells has increased rapidly over the past few years.

\section{Turn off Monitors \& Hard Disk}

Through turning off monitor one can accumulate half the energy that is used with the system. Thus turn off the monitor while, download in progress or else while it is in idle intended for a few minutes. Use LED, LCD monitors instead of CRTs it determination reduce many of power. One can automate throughout this option. Depending uop the usage monitor may be turn off if it is idle intened for 10 minutes. Similarly hard disk may also be turn off if it is idle. This kind of settings may be done if towards 30 minutes depending upon the usage.

\section{Advantages of Green Computing}

- Lower carbondioxide emissions

- Reduction in the fossil fuel

- Less energy towards produce, use and dispose of products

- Recycling in support of Government

- It reduces the risk existing through thee laptops sucs as chemicals which lead towards the cause of nerve damage, cancer etc..

- Efficiency and Improved Performance

- Saving energy in addition to resources saves money

Environmental Sustainability all through the entire IT lifecycle, making it greener by means of addressing by addressing key areas including:

- Green use

- Green disposal

- Green design

- Green manufacturing

\section{CONCLUSION}

Technology is ever changing in addition to expanding which encourages folks towards use computers in addition to accessories so as to are environmentally friendly along with that cause little or else no harm towards the environment throughout their usage or else while they are disposed off.

\section{REFERENCES}

[1] University of Guelph. 2005. From the president more Budget Challenges lie ahead for U of G [Online]. Accessed March 28, 2005.

[2] Vyacheslav Kharchenko1, Oleg Illiashenko1, Chris Phillips2, Juri Vain3 Green Computing and TEMPUS Projects Activities conference paper

[3] Wang, Feng, J. Huisman, C. Meskers, M. Schluep, A. Stevels, C. Hageluken (Wang et al). "The Best-of-2 Worlds philosophy: Developing 
local dismantling and global infrastructure network for sustainable ewaste treatment in emerging economies." Waste Management 32 (2012) 2134-2146. Elsevier. Web. 4 February 2013.

[4] Webb M (2008) SMART 2020: Enabling the low carbon economy in the information age. Tech. rep, Climate Group on behalf of the Global eSustainability Initiative (GeSI)

[5] Widmer R., Global perspectives on e-waste, Environmental Impact Assessment Review, 25, 436- 458, 2005.

[6] Williams, E. 2003. Environmental Impacts in the Production of Personal Computers. In Kuehr, R. and Williams, E (Eds.). Computers and the Environment: Understanding and Managing Their Impacts. London: Kluwer Academic Publishers.

[7] Williams, E.: Energy Intensity of Computer Manufacturing: Hybrid Assessment CombiningProcess and Economic Input-Output Methods. Environmental Science and Technology. Vol.38, Issue. 22, pp. 61666174 (2004)

[8] Zhang, S. and Forssberg. E. 1999. Intelligent Liberation and classification of electronic scrap. Powder technology 105: 295-301 